\title{
Ultimate lateral load resistance of laterally loaded pile
}

Md. M. Rahman

Assistant Professor, Department of Civil Engineering, RUET, Rajshahi, Bangladesh

Md. R. Karim, A. L. Baki \& D. K. Paul

Lecturer, Department of Civil Engineering, RUET, Rajshahi, Bangladesh

ABSTRACT: Several methods are available for predicting ultimate lateral load resistance of laterally loaded pile. These methods often produce significantly different ultimate lateral resistance. This makes it difficult to select an appropriate method in designing/predicting ultimate lateral resistance of pile. This paper presents a review of two different methods; Meyerhof and Patra \& Pise for predicting lateral resistance of pile. Then, the predicted ultimate lateral resistances by these two methods are compared with the experimental results. It is found that Meyerhof's method gives better prediction for single pile with smaller L/d ratio whereas Patra \& Pise method gives better predictions for pile groups with higher L/d. Thus, none of these methods can be applicable universally for all possible conditions. Also the parametric study on ultimate lateral resistance revealed that length to diameter ratio, pile spacing, pile configuration in a pile group are important parameters for prediction of lateral load resistance.

\section{INTRODUCTION}

There are several approaches are available in the literature to estimate lateral load resistance of pile in sand and clay (Broms 1964; Meyerhof et al. 1981; Meyerhof and Ranjan 1972; Meyerhof and Sastry 1985; Meyerhof and Yalcin 1984; Sastry 1977; Sastry and Meyerhof 1986; Zhang et al. 2005). Also some simplified methods are proposed by Meyerhof et al. (1988) and Patra \& Pise (2001) for cohesionless soil. However, these methods often produce significantly different ultimate lateral load resistance value (Zhang et al. 2005). This makes it difficult to select appropriate method when designing laterally loaded pile in cohesionless soil. A comparative study has been made in this paper between Mayerhof and Patra \& Pise methods and experimental results with the intension that it could add some value on the understanding of practicing engineers. Also a parametric study is done on ultimate lateral load resistance. They are discussed in coming sections.

\section{ULTIMATE LATERAL LOAD RESISTANCE}

The simplified methods proposed by Meyerhof et al. (1988) and Patra \& Pise (2001) has been briefly reviewed in this section. These methods are approximate with considerable assumptions. They are discussed in coming subsections.

\subsection{Meyerhof's method}

The ultimate lateral resistance of rigid pile, $Q_{\mathrm{ur}}$ is expressed by Meyerhof et al.(1981) as

$Q_{u r}=0.12 \gamma d L^{2} K_{b}$

Where $\gamma$ is average unit weight of sand; $d$ is the diameter of pile; $L$ is embedded length of pile; $K_{\mathrm{b}}$ is coefficient of net passive earth pressure on pile using an average angle of skin friction $\delta=\varphi / 3$. Where $\varphi$ is the angle of internal friction. However the ultimate lateral load resistance of flexible pile was presented by Meyerhof et al. (1988) as

$Q_{u r}=0.12 \gamma d L_{e}^{2} K_{b}$

Where $L_{\mathrm{e}}$ is the effective embedded length of flexible pile. Meyerhof and Yalcin (1984) suggested that if relative stiffness ratio $K_{\mathrm{rs}}$ is less than $10^{-1}$ to $10^{-2}$ then the pile can be consider as flexible pile. However, the relative stiffness, $K_{\mathrm{rs}}$ can be presented as

$$
K_{r s}=E_{p} I_{p} / E_{h} L^{4}
$$

Where $E_{\mathrm{p}}$ is modulus of elasticity of pile; $I_{\mathrm{p}}$ is moment of inertia of pile; $E_{\mathrm{h}}$ is horizontal soil modulus at pile tip; $L$ is embedded length of pile. Meyerhof et al. (1988) reported that $L_{\mathrm{e}} / L$ has an approximate functional relationship with relative stiffness $K_{\mathrm{rs}}$ and it can be presented as 


$$
L_{e} / L=1.8 K_{r s}^{0.12}
$$

However, Rahman et al. (2003) reported that $L_{\mathrm{e}} / L$ can be represent by following relation as

$$
L_{e} / L=1.65 K_{r s}^{0.12}
$$

\subsection{Patra \& Pise method}

Patra \& Pise (2001) modified the Meyerhof's equation by multiplying a constant shape factor of 3 with the line of Broms (1964)

$$
Q_{u r}=3 \times 0.12 \gamma d L_{e}^{2} K_{b}
$$

\subsection{Pile group}

Patra \& Pise (2001) reported that the ultimate resistance of the pile group can be represented by

$$
Q_{L g}=2 F+P_{P}
$$

Where, $Q_{\mathrm{Lg}}$ is ultimate lateral resistance of the pile group, $F$ is frictional resistance on the vertical plane along the side of the pile group of width equal to centre to centre distance between external piles and embedded length $L$ and $P_{p}$ passive earth pressure for the front pile as shown in Figure 1.

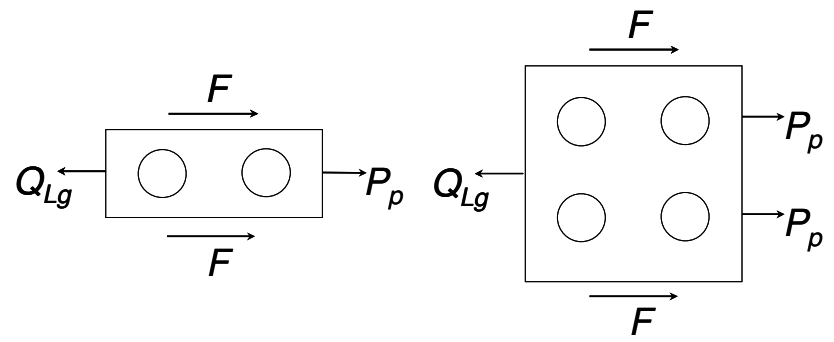

Figure 1. Free body diagram of laterally loaded pile group

The frictional resistance along the side of the pile group could be approximately found as

$F=\frac{1}{2} \chi^{2} \times K_{S} S$

Where, $K_{\mathrm{s}}$ is coefficient of earth pressure along the side of the piles group governing frictional resis$\operatorname{tance}[(1-\sin \varphi) \tan \delta]$. Thus, ultimate lateral resistance of pile group, $2 \times 1$ is

$$
Q_{L g}=\varkappa^{2}\left[K_{s} S+0.36 d K_{b}\right]
$$

And the ultimate resistance of pile group, $2 \times 2$ can be expressed as

$Q_{L g}=\mathcal{L}^{2}\left[K_{s} S+0.72 d K_{b}\right]$

\subsection{Group efficiency}

The efficiency of ultimate lateral resistance of pile group can be expressed as

$\eta=\frac{Q_{L g}}{n_{1} n_{2} Q_{L s}}$

Where $Q_{L g}$ is the ultimate lateral capacity of pile group; $Q_{L s}$ is the ultimate lateral capacity of single pile; $n_{1}$ is the number of rows in the pile group and $n_{2}$ is the number of columns in the pile group.

\section{EXPERIMENTATION}

An experimental program was designed for the verification and comparison of the above mention methods. The details of the experimental program and material properties such as sand, pile, pile cap etc. are given in following subsections.

\subsection{Foundation}

Rajshahi sand (available in north-west region in Bangladesh) is used as foundation medium. All model pile tests were done on a concrete tank of one meter in height, one meter in width and one meter in depth. Sand had a placement density of $95 \mathrm{lb} / \mathrm{ft} 3$ or $15 \mathrm{kN} / \mathrm{m}^{3}$ and the angle of internal friction was $37.9^{\circ}$. Specific gravity of the sand used in the model tank was 1.82 .

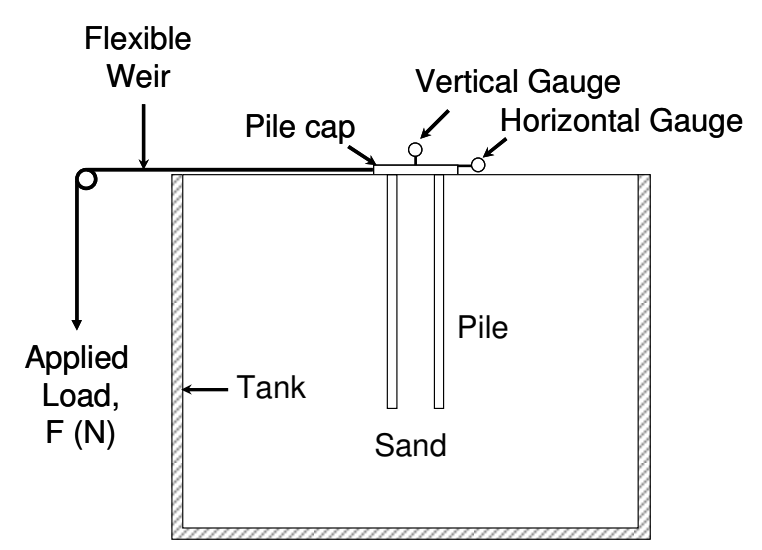

Figure 2. Experimental arrangement for laterally loaded pile

\subsection{Pile and pile cap}

Aluminum alloy tube of $19 \mathrm{~mm}$ outer diameter and $0.81 \mathrm{~mm}$ wall thickness were used as model pile. To increase the pile wall friction angle, sand was added around the pile by adhesives. The average outside diameter of the rough piles were $20 \mathrm{~mm}$. The embedment length-to-diameter ratios, L/d were 20, 30, and 35 . Steel plate of $0.64 \mathrm{~cm}$ thickness was used as pile cap. The piles were attached with the pile cap by screw. The details of sand and piles properties can 
be found in (Rahman et al. 2003). The pile groups used in this study had configurations of $2 \times 1$ and $2 \times 2$.

\subsection{Experimental procedure}

The arrangement of test program is shown in Figure 2. The Loading arrangement was made in such a way that it acted laterally to pile or pile cap. However, it was not possible to apply continuous loading but load is applied by stepping. To maintain a uniform density all through the tank depth, sand was placed in the tank from a constant height of about $0.5 \mathrm{~m}$. After filling the tank, the upper surface of sand was leveled and then the pile was pushed into sand. Pile cap was then fixed on the pile top with screw connections. A 24 hours of rest period was allowed before applying any load on pile setup. The lateral load was applied to the pile cap through a pulley arrangement with flexible weir. The other end of the weir was attached to the loading apron. Load was applied by dead weight over the loading pan starting form the smallest with gradual increase in steps. To measure the lateral and vertical deflection dial gauges with a sensitivity of $0.01 \mathrm{~mm}$ were used. When step by step lateral loads were applied on the pile or pile group, they were deflected in the direction of the lateral load and the dial gauge readings and the corresponding loadings were recorded.

\section{RESULTS}

The ultimate lateral load resistance of the pile was worked out by plotting the recorded data, thus load Vs deflection curve was obtain which was non-linear in nature. Ultimate lateral resistance of the pile was obtained from the curve by double tangent method (DTM) or the point where the curve show a greater deflection without further increase in any load. The detail can be found in (Rahman et al. 2003). The curves presented in this paper are only showing the general trends. The ultimate load resistance behaviours of single pile and the pile group are presented in coming subsections.

\subsection{Single pile}

The ultimate lateral load resistance of single pile increases with increase in L/d ratio as shown in Figure 3 . The ultimate load resistance of a single pile for $\mathrm{L} / \mathrm{d}=20$ is about $107 \mathrm{~N}$ whereas $115.2 \mathrm{~N}$ predicted by Meyerhof's method and $72 \mathrm{~N}$ by Patra \& Pise method. Thus, Patra \& Pise method doesn't predict well for single pile and the prediction by Meyerhof's method is very closed to the experimental observation. However, in higher L/d, Patra \& Pise method gives better prediction. The ultimate lateral load resistance of $\mathrm{L} / \mathrm{d}=35$ is about $225 \mathrm{~N}$ and Patra \& Pise method predicted $221.7 \mathrm{~N}$ whereas Meyerhof's prediction deviate by $50 \mathrm{~N}$ in higher side.

\subsection{Pile group, $2 x 1$}

The ultimate lateral load resistance of pile group, $2 \times 1$ increases with increasing $\mathrm{L} / \mathrm{d}$ as shown in Figure 4. It is about $117.2 \mathrm{~N}$ for $\mathrm{L} / \mathrm{d}=20$ and $160 \mathrm{~N}, 250 \mathrm{~N}$ for $\mathrm{L} / \mathrm{d}=30, \mathrm{~L} / \mathrm{d}=35$ respectively.

However, when the observed ultimate lateral resistance is compared with Mayerhof and Patra \& Pise methods, it is found that the ultimate lateral load resistance predicted by Patra \& Pise method gives a better prediction for pile group. Table 1 . shows the detailed results for $\mathrm{L} / \mathrm{d}=20$.

Table 1. Comparison of lateral load resistance of pile group, 2x1 with Patra \& Pise method and observed value.

\begin{tabular}{llll}
\hline L/d ratio & $\begin{array}{l}\text { Spacing } \\
(\mathrm{d})\end{array}$ & $\begin{array}{l}\text { Observed re- } \\
\text { sistance }(\mathrm{N})\end{array}$ & $\begin{array}{l}\text { Theoretical } \\
\text { resistance } \\
(\mathrm{N})\end{array}$ \\
\hline 20 & 3.0 & 117.2 & 115.6 \\
20 & 4.5 & 147.0 & 137.2 \\
20 & 6.0 & 166.0 & 158.8 \\
\hline
\end{tabular}

\subsection{Pile group, $2 \times 2$}

The load deflection curve for pile group, $2 \times 2$ is shown in Figure 5. This figure only shows two different $\mathrm{L} / \mathrm{ds}$ and it clearly shows that ultimate lateral load resistance of pile increases with its $\mathrm{L} / \mathrm{d}$ ratio. The ultimate lateral load resistances are $200 \mathrm{~N}$ and $300 \mathrm{~N}$ for $\mathrm{L} / \mathrm{d}=20$ and $\mathrm{L} / \mathrm{d}=30$ respectively. However, the ultimate lateral load resistances predicted by Patra-Pise methods are $190 \mathrm{~N}$ and $280 \mathrm{~N}$ respectively. Again, it indicates that this method could better and conservative prediction.

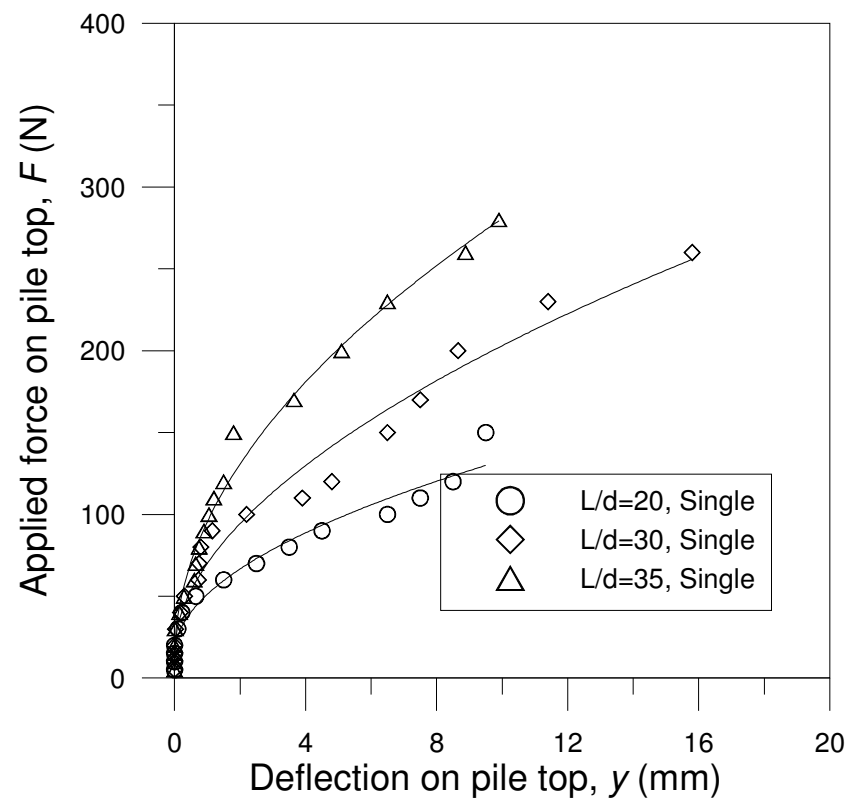

Figure 3. Load deflection curve for single piles for different $\mathrm{L} / \mathrm{d}$ ratios. 


\subsection{Effect of pile spacing in group}

Figure 6 shows that the centre to centre distance of piles in a group has strong influence on the ultimate lateral resistance of pile; it increases with increasing in piles $\mathrm{c} / \mathrm{c}$ distance. However, the variation with $\mathrm{c} / \mathrm{c}$ distance of piles is not linear. Figure 7 shows that the increment of lateral resistance for $3.0 \mathrm{~d}$ to $4.5 \mathrm{~d}$ is higher than the increment for $4.5 \mathrm{~d}$ to $6.0 \mathrm{~d}$.

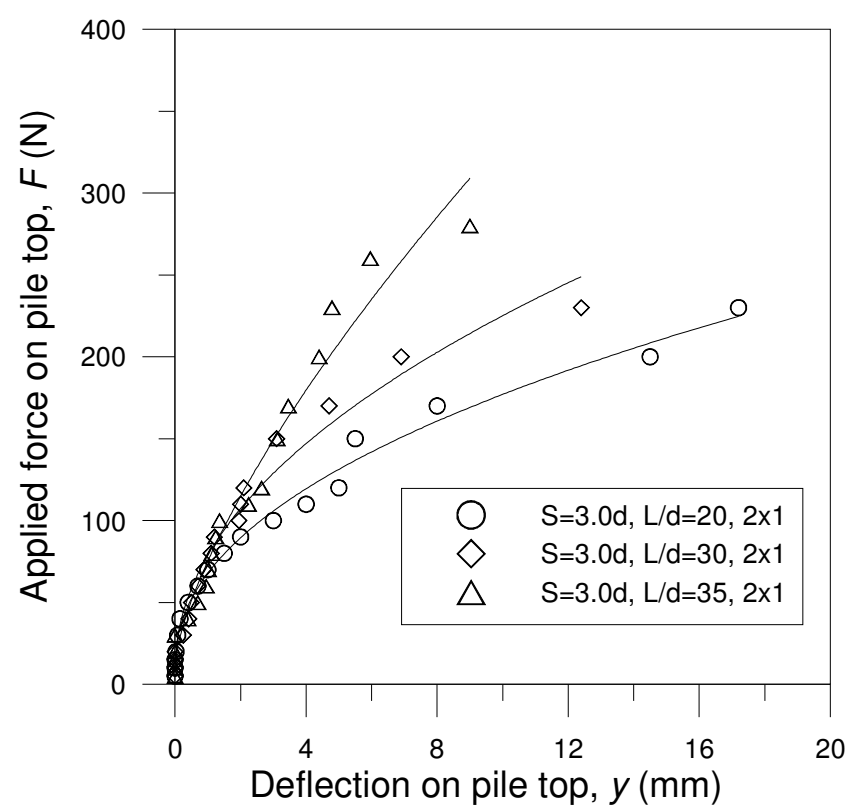

Figure 4. Load-deflection curve for pile group, $2 \mathrm{x} 1$

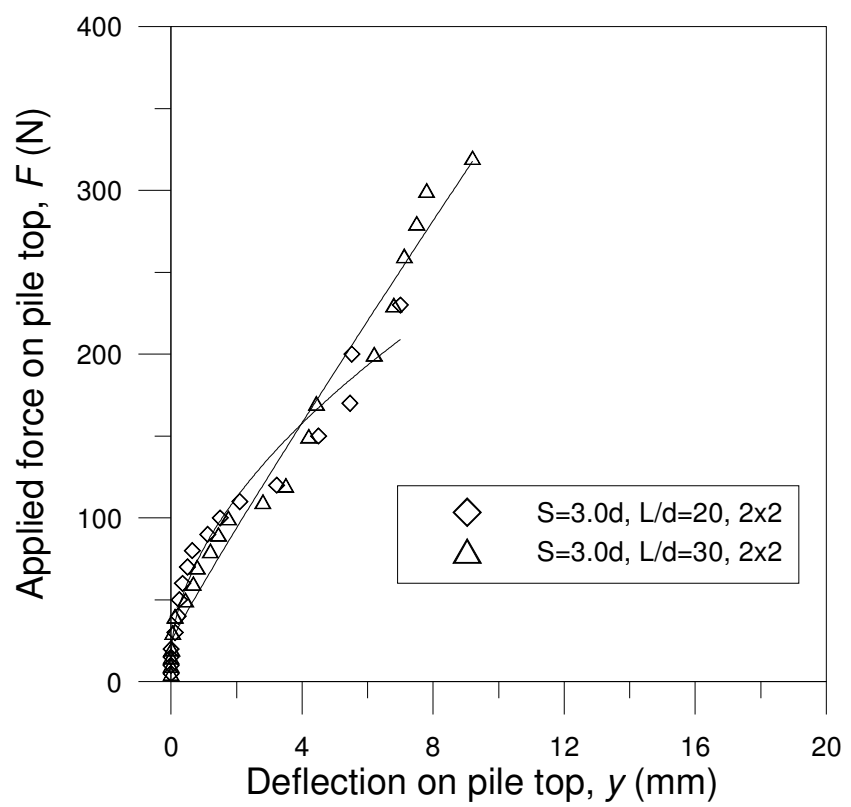

Figure 5. Load-deflection curve for pile group, $2 \times 2$

\subsection{Group efficiency}

The efficiency of lateral load resistance for pile group is calculated by the Equation 11 and they are presented in Figure 7. It shows that the increment of group efficiency for $3.0 \mathrm{~d}$ to 4.5 is maximum and it reduces from $4.5 \mathrm{~d}$ to $6.0 \mathrm{~d}$. This trend is seen in both groups of $2 \times 1$ and $2 \times 2$. However, it is interesting to note that group efficiency for the group of $2 \times 2$ is less than for the group of $2 \times 1$. Thus, it indicates that pile spacing also very important for ultimate lateral resistance of pile.

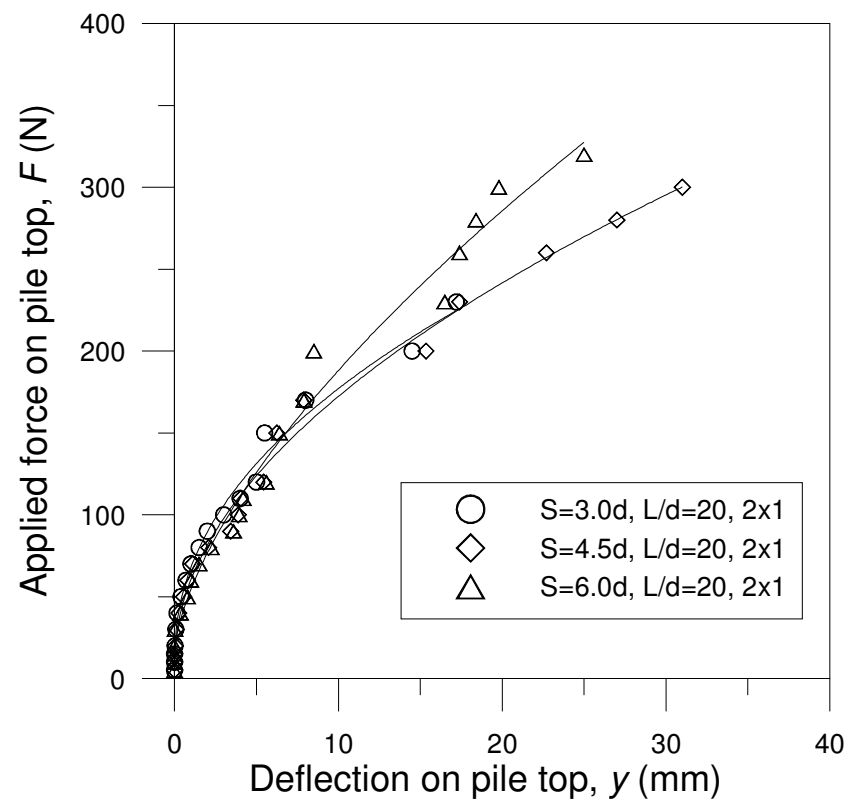

Figure 6. The effect of centre to centre distance between piles in group, $2 \times 1$.

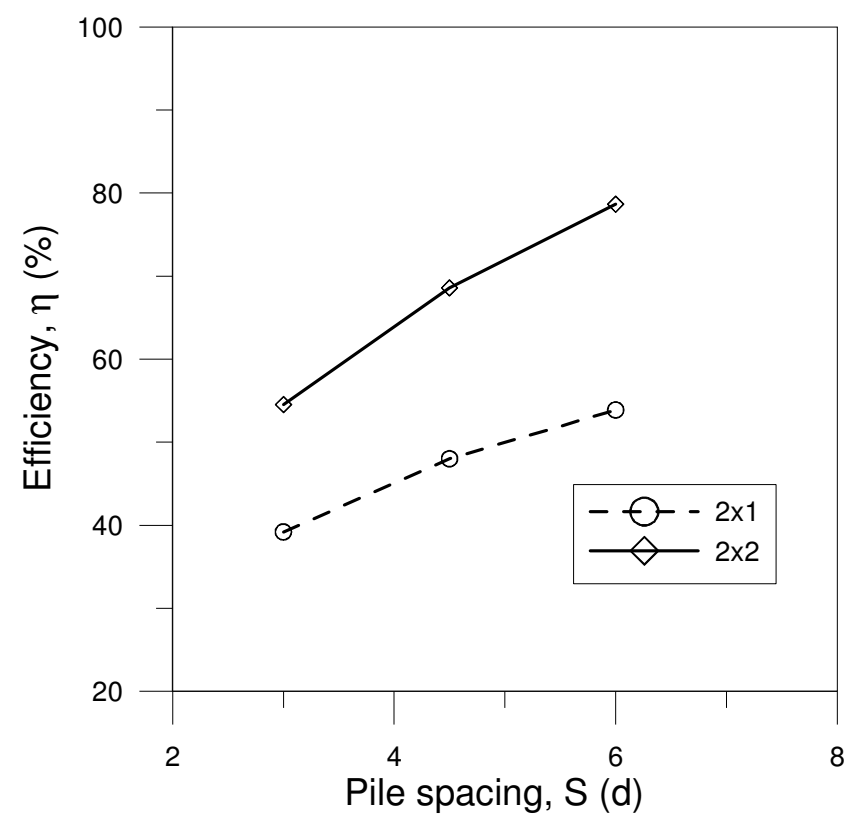

Figure 7. Variation of pile group efficiency with pile spacing between group, $2 \times 1$ and group, $2 \times 2$.

\section{CONCLUSIONS}

The following conclusions are drawn from the present study:

- The ultimate lateral load resistance of pile group depends on the length to diameter ratio of pile, pile friction angle, pile group geometry, spacing of piles in a group and sand placement density. The quantitative and 
qualitative influence of those parameters has been investigated.

- The ultimate resistance of pile group increases with an increase in pile spacing. It has been found that resistance at $3 \mathrm{~d}$ spacing is less than that of $4.5 \mathrm{~d}$ spacing. Again resistance at $4.5 \mathrm{~d}$ spacing also less than that of $6 \mathrm{~d}$ spacing.

- Group efficiency of pile increases with an increase in pile spacing. It has also been found that the efficiency at $3 \mathrm{~d}$ spacing is less than that of $4.5 \mathrm{~d}$ and $6 \mathrm{~d}$ spacing.

- Finally, the prediction by Patra \& Pise method can give better prediction for pile groups whereas Meyerhof's method gives better prediction for single pile. Thus, none of these can be universally used for the prediction of lateral load resistances of pile or pile group.

\section{REFERENCES}

Broms, B. B. 1964. Lateral resistance of piles in cohesionless soils. Journal of the Soil Mechanics and Foundations Division, ASCE, 90(SM3): 123-156.

Meyerhof, G. G., Mathur, S. K., and Valsangkar, A. J. 1981. Lateral Resistance and Deflection of Rigid Walls and Piles in Layered Soils. Canadian Geotechnical Journal, 18(2): 159-170.

Meyerhof, G. G., and Ranjan, G. 1972. The bearing capacity of rigid piles under inclined load in sand. I. Vertical Piles. Canadian Geotechnical Journal, 9, 430-446.

Meyerhof, G. G., Sastry, V., and Yalcin, A. S. 1988. Lateral Resistance and Deflection of Flexible Piles. Canadian Geotechnical Journal, 25(3): 511-522.

Meyerhof, G. G., and Sastry, V. V. R. N. 1985. Bearing capacity of rigid piles under eccentric and inclined loads. Canadian Geotechnical Journal, 22, 267-276.

Meyerhof, G. G., and Yalcin, A. S. 1984. Pile capacity for eccentric inclined load in clay. Canadian Geotechnical Journal, 21, 389-396.

Patra, N. R., and Pise, P. J. 2001. Ultimate lateral resistance of pile groups in sand. Journal of Geotechnical and Geoenvironmental Engineering, 127(6): 481-487.

Rahman, M. M., Alim, M. A., and Chowdhury, M. A. S. 2003. Investigation of lateral load resistance of laterally loaded pile in sandy soil. 4th International Conference on Bored and Auger Piles, BAPIV, Ghent, Belgium, 209-215.

Sastry, V. V. R. N. 1977. Bearing capacity of piles in layered soil, PhD Thesis, Technical University of Nova Scotia, Halifax, NS.

Sastry, V. V. R. N., and Meyerhof, G. G. 1986. Lateral soil pressures and displacements of rigid piles in homogeneous soils under eccentric and inclined loads. Canadian Geotechnical Journal, 23, 281-286.

Zhang, L., Silva, F., and Grismala, R. 2005. Ultimate Lateral resistance to piles in cohesion less soils. Journal of Geotechnical and Geoenvironmental Engineering, 131(1): 7883. 